\title{
School performance and undetected and untreated visual problems in schoolchildren in Ireland; a population-based cross- sectional study
}

\author{
Síofra Harrington \\ Technological University Dublin, siofra.harrington@tudublin.ie \\ Peter Davison \\ Technological University Dublin, Peter.Davison@tudublin.ie \\ Veronica O'Dwyer \\ Technological University Dublin, veronica.odwyer@tudublin.ie
}

Follow this and additional works at: https://arrow.tudublin.ie/scschphyart

Part of the Optometry Commons

\section{Recommended Citation}

Siofra Harrington, Peter A. Davison \& Veronica O'Dwyer (2021): School performance and undetected and untreated visual problems in schoolchildren in Ireland; a population-based cross-sectional study, Irish Educational Studies, DOI: 10.1080/03323315.2021.1899024

This Article is brought to you for free and open access by the School of Physics \& Clinical \& Optometric Science at ARROW@TU Dublin. It has been accepted for inclusion in Articles by an authorized administrator of ARROW@TU Dublin. For more information, please contact arrow.admin@tudublin.ie, aisling.coyne@tudublin.ie, gerard.connolly@tudublin.ie.

Funder: TU Dublin; Irish Opticians Board; Association of Optometrists Ireland

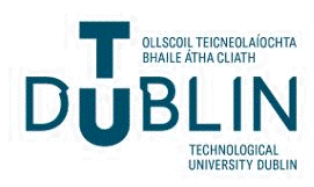




\section{School performance and undetected and untreated visual problems in schoolchildren in Ireland; a population-based cross-sectional study}

\section{Siofra Harrington, Peter A. Davison \& Veronica O'Dwyer}

To cite this article: Siofra Harrington, Peter A. Davison \& Veronica O'Dwyer (2021): School performance and undetected and untreated visual problems in schoolchildren in Ireland; a population-based cross-sectional study, Irish Educational Studies, DOI: 10.1080/03323315.2021.1899024

To link to this article: https://doi.org/10.1080/03323315.2021.1899024

Published online: 23 Apr 2021.

Submit your article to this journal $\sqsubset$

Q View related articles ¿

View Crossmark data 


\title{
School performance and undetected and untreated visual problems in schoolchildren in Ireland; a population-based cross-sectional study
}

\author{
Siofra Harrington $\mathbb{B}^{*}$ *, Peter A. Davison and Veronica O’Dwyer \\ School of Physical and Clinical and Optometric Sciences, Technological University Dublin, \\ Dublin, Ireland
}

(Received 17 February 2020; accepted 10 December 2020)

This study explored the association between children's vision and their school academic progress as reported by parents/guardians. Participants were 1,612 schoolchildren (722 6-7-year-olds, 890 12-13-year-olds) in randomly selected schools in Ireland. In advance of data collection, parents/guardians reported school performance as (a) much better than classmates (high-performance) (b) about the same as classmates (average-performance) (c) not as well as classmates (low-performance). Measurements included logMAR monocular visual acuities (with spectacles if worn, and pinhole) in the distance $(3 \mathrm{~m})$ and near $(40 \mathrm{~cm})$; the amplitude of accommodation; stereoacuity, colour vision assessment, and cyclopleged autorefraction.

Controlling for confounders, children presenting with visual impairment (vision poorer than $0.3 \log$ MAR $(6 / 12)$ in the 'better eye'), amblyopia ('lazy eye'), uncorrected refractive error (hyperopia $\geq+3.50 \mathrm{D}$ and astigmatism $\geq 1.50 \mathrm{DC}$ ), reduced for age ability to adjust focus from distance to near tasks (accommodation), impaired three-dimensional vision (stereoacuity), and defective colour vision were more likely to report low-performance in school. The majority of low-performing participants $(68 \%)$ did not have an eye examination within the 12 months before data collection. Children with academic performance challenges ought to have a comprehensive eye examination, to detect potential vision problems for early intervention minimising any negative impact they may have on educational outcomes.

Keywords: School performance; vision; visual impairment; amblyopia; refractive error

\section{Introduction}

Research suggests that up to $80 \%$ of what children learn in school is acquired visually (Ehri 2005; Scheiman and Rouse 2006; Sylva 1997). For example, 70-80\% of a typical school day involves visual-based tasks, of which half are sustained near visual tasks (Narayanasamy et al. 2016; Negiloni, Ramani, and Sudhir 2017). Good vision is essential to learn efficiently and succeed in school. Untreated, visual impairments in childhood, can result in developmental delay; limiting educational achievement, reducing employment opportunities and social engagement (Skarzyński and Piotrowska 2012). Schoolchildren need many visual skills to learn including adequate visual acuity (VA) to distinguish details on blackboards or whiteboards (distance),

\footnotetext{
* Corresponding author. Email: siofra.harrington@tudublin.ie 
computer screens (intermediate), and written material/books (near) and to quickly and accurately adjust the eyes focus between these tasks (Li 2004). Other visual abilities required include coordinating the use of two eyes together when moving eyes across a page or judging depth and distances (Taylor-Kulp 1999). Moreover, learning requires the ability to make sense of what we see (visual perception) which involves recognition, comprehension and retention (Goldstand, Koslowe, and Parush 2005). Accordingly, the link between vision and academic performance has been observed in many studies which addressed specific aspects of visual function such as VA (Kulp and Schmidt 1996), stereoacuity (three-dimensional image) (Ponsonby et al. 2013), uncorrected refractive error (myopia (nearsightedness), hyperopia (longsightedness) and astigmatism (distorted vision due to irregular cornea or lens) (VIP-HIP Study Group 2016)), inadequate binocular vision status and delayed visual processing (Christian et al. 2018; Hopkins et al. 2019). However, no study has examined the collective influence of these and other factors such as colour vision deficiency on school performance.

Vision appears to be strongly associated with learning in the "learn to read' stage (<8-years-old) where there is a significant demand on the visual system when decoding text (Chen, Bleything, and Lim 2011). Whereas visual requirements change during the 'read to learn' stage (>8-years-old); print size decreases, the amount of time spent reading and studying increases, thus increasing visual demand (Legge and Bigelow 2011; Wilkins et al. 2009), and fast, automatic decoding is required as the emphasis is on comprehension. Children with special educational needs benefit measurably from in-school comprehensive eyecare and spectacle provision (Black et al. 2019). However, results regarding the association between vision and school performance in typically developing children have been inconsistent; some studies have found an association (Bruce et al. 2016; Wood et al. 2018), while other studies have not (Dirani, Shekar, and Baird 2008; Helveston et al. 1985).

Many studies established an association between myopia and intelligence measures (Onal et al. 2007; Williams, Miller, and Saw 2008), however, in contrast, hyperopia is associated with reading difficulties (Ip et al. 2008), educational underperformance (Stewart-Brown, Haslum, and Butler 2008; Williams, Miller, and Saw 2008), and developmental deficits (Atkinson et al. 2002). Children with amblyopia ('lazy eye') read more slowly (Kelly et al. 2015), and take significantly longer to complete a multiple-choice form despite being provided with the correct answers when compared to a control group (Kelly et al. 2018). Academic challenges in school due to defective colour vision (Gallo et al. 2003), and amblyopia (Carlton and Kaltenthaler 2011) can result in low self-esteem and feelings of inferiority. Unaddressed visual issues have negative consequences for both the individual, in terms of diminished educational opportunities (Khalaj et al. 2011), and reduced quality of life (Carlton and Kaltenthaler 2011), with implications beyond school years affecting employment options; additionally impacting the broader community in terms of higher healthcare expenditure and lost output (Rahi and Gilbert 2012).

Therefore, addressing vision disorders in early childhood, ideally in advance of commencing school (Roch-Levecq 2008), is essential to prevent them from impacting on children's education, social and physical development (Birch et al. 2018; Webber 2018). This is the first study in Ireland to examine the relationship between parents/guardians' perception of their children's school academic progress in mainstream school and various aspects of vision. The present study examined the 
collective influence of a wide range of vision variables on parent-reported school performance using multinomial logistic regression.

\section{Methodology}

Sampling, recruitment protocols, participation rates, experimental techniques and methods employed are previously described in detail (Harrington et al. 2019a). The present study adopted protocols and sampling measures used in population-based international studies (Negrel et al. 2000; Ojaimi et al. 2005; O'Donoghue et al. 2010, Logan et al. 2011), designed to assess refractive error and visual impairment in children, where sample sizes were based on estimating the age-specific myopia prevalence in the study population. In summary, sample size calculations, using $\mathrm{G}^{*}$ Power $^{1}$ analysis, were based on a $3-5 \%$ myopia prevalence with a $1.0 \%$ standard error for 6-7-year-olds and 10\% prevalence with $1.5 \%$ standard error for $12-13$ year-olds. The sample was inflated to allow for clustering within schools and a $75 \%$ participation rate. Therefore, a minimum of seven hundred 6-7-year-old and eight hundred 12-13-year-old children was required. Stratified random sampling was used to obtain representative samples of children in mainstream schools in Ireland. Schools were categorised by primary/post-primary status, urban/rural status and socioeconomic status. The Irish state supports schools designated as Delivering Equality of opportunity In School (DEIS). This study categorised socioeconomic status by DEIS status: DEIS schools were defined as socioeconomically disadvantaged, other schools were defined as advantaged. The Technological University Dublin Research Ethics Committee granted ethical approval, and the study was carried out in compliance with the tenets of the Declaration of Helsinki.

Public involvement: During the design stage of the study, focus groups assessed the burden associated with, and the time to complete the study questionnaire (Collins 2003). Focus group feedback, to improve the study accessibility, shortened the questionnaire, simplified the wording, and added a statement advising parents/guardians to skip any questions they felt uncomfortable answering. Furthermore, a storyboard, outlining the examination, was designed to make the study clear to children. Additionally, focus group feedback revealed objectively measured academic scores and teacherreported findings of participants' school performance would not be acceptable to some parents of low-performing children. This could have compromised the questionnaire response rate and negatively impacted on participants engaging with the study. Hence, the study used parent/guardian reports as a proxy for school performance. Previous research found parental reports are as accurate as standardised testing or professional opinion (Diamond 1987; Diamond and Squires 1993; Glascoe 1997).

Children with written informed consent and child assent were examined on their school premises within school hours. Data collection was conducted between June 2016 and January 2018 by the first author (Dr Síofra Harrington), a trained optometrist. Participants were 1,626 schoolchildren in Ireland: 728 participants aged 6-7-years-old ( 377 boys and 351 girls) and 898 participants aged 12-13-years-old (504 boys and 394 girls). Ethnicity was as follows: White (1290 participants), Traveller (156 participants) or non-White (combined: Black 80, East Asian 51, and South Asian 49). The Traveller community is Ireland's largest indigenous ethnic minority (Gilbert et al. 2017).

Participants' parents/guardians completed a standardised questionnaire reporting inter-alia, eye and vision problems, medical and previous eye examination and 
parent-reported school performance. They returned it to the first author in advance of data collection. The questionnaire parent-reported school performance response options were: (a) much better than classmates; (b) about the same as classmates; (c) not as well as classmates. Henceforth referred to as high-performance, averageperformance and low-performance in line with the Programme for International Student Assessment (PISA) worldwide study by the Organisation for Economic Co-operation and Development (OECD) categories (OECD 2016).

\section{Examinations}

Distance vision ( $3 \mathrm{~m}$ ): monocular logMAR presenting (with spectacles if worn) VA was measured and scored by-letter with and without a pinhole using the Good-Lite (Elgin, Illinois) Sloan letters $\log$ MAR chart. A matching card was available for participants unable to name the letters. Near vision $(40 \mathrm{~cm})$ : monocular $\log$ MAR presenting VA was measured using the Sonsken logMAR near test chart (Novomed limited, Maidstone, ME199AG, UK). Stereovision: The TNO anaglyph stereo-test (Richmond products, South San Francisco, CA 94080, USA) was used to quantify the degree of stereoacuity. Amplitude of accommodation (this is the maximum measure of accommodative function (the ability of the eye to change its focus from distant to near objects) that can be observed) was measured binocularly using the Royal-Air-Force rule push-up method; participants reported when the target brought gradually nearer their eyes became blurred. Ocular alignment was evaluated to check for the presence of strabismus (misaligned eyes) using a cover-uncover test, and an alternating cover test, using an accommodative target with and without spectacle correction (if worn) at $3 \mathrm{~m}$ and $40 \mathrm{~cm}$. The Richmond Hardy-Rand-Rittler fourth edition, colour-vision test was performed with the habitual prescription in place at a distance of $70 \mathrm{~cm}$ in natural daylight. Cycloplegic autorefraction was performed at least $20 \mathrm{~min}$ and not more than $45 \mathrm{~min}$ post instillation of anaesthetic (Minims Proxymetacaine Hydrochloride $0.5 \% \mathrm{w} / \mathrm{v}$, Bausch \& Lomb, UK) and cycloplegic eye drops (Minims Cyclopentolate Hydrochloride 1\% w/v, Bausch \& Lomb, UK). Cycloplegic refraction is the gold standard for measuring refractive errors in children; the eye drops temporarily paralyse the focusing system of the eye. Non-cycloplegic refraction can result in overdiagnosis of short-sightedness and underestimation of long-sightedness (Li et al. 2019). The representative value for SER - sphere plus half the cylindrical value - was used in subsequent analysis.

Definitions: Presenting visual impairment (PVI) was presenting VA $>0.30 \log$ MAR (worse than 6/12 Snellen) in the 'better eye' (Smith et al. 2009). Amblyopia was defined as pinhole acuity $\geq 0.3 \log$ MAR in the affected eye, plus the presence of an amblyogenic factor (Xiao et al. 2015). Clinically significant refractive errors were: myopia SER $\leq-1.00$ dioptre $^{2}(\mathrm{D})$, hyperopia $\geq 3.50 \mathrm{D}$, astigmatism $\geq 1.50$ dioptre cylinder (DC) ${ }^{3}$ (O'Donoghue et al. 2012). Follow up: Subsequent to the examination, all parents/guardians received a detailed report advising them of study findings and the necessity of any further treatment if required.

\section{Statistical methodology}

Multinomial logistic regression analysis, with participants who reported average-performance as the reference category, was employed to examine the relationship of 
parent-reported school performance with categorical variables (myopia, hyperopia, astigmatism, amblyopia, stereoacuity status, PVI and colour-vision) while controlling for confounders (ethnicity, socioeconomic status and gender). Presenting vision ( $\log$ MAR), stereoacuity (arc-seconds) and amplitude of accommodation (D) were analysed as continuous variables in the multiple linear regression models. The distribution of right and left eye data were significantly correlated for distance VA (Pearson correlation: 6-7-years-old $\mathrm{r}=0.77,12$-13-years-old $\mathrm{r}=0.65$, overall $\mathrm{r}=0.71$ (all $p<0.001)$ ), and near VA (Pearson correlation: 6-7 years $\mathrm{r}=0.85,12-13$-years-old $r=0.55$, overall $r=0.76($ all $p<0.001)$ ). Hence, data are presented for the right eye only unless otherwise stated; amblyopia means amblyopic in either eye or both. $P$ values $\leq 0.05$ were regarded as significant. Throughout, $95 \%$ confidence intervals (CI) were used.

\section{Results}

Statistical analysis of study questionnaires and examination results included 722 of the 728 6-7-year-olds (response-rate $=99.2 \%$ ) and 890 of the 89812 13-year-olds (response-rate $=99.1 \%$ ). Their parents/guardians reported $9 \%$ $(67 / 722)$ of 6-7-year-old and $6 \%(55 / 890)$ of 12-13-year-old participants as low-performing.

\section{Sociodemographic Factors associated with school performance}

Logistic regression analysis showed high-performance was associated with older age-group $(\mathrm{OR}=1.5, \mathrm{CI}: 1.1-1.9, p=0.006)$, urban living $(\mathrm{OR}=1.8, \mathrm{CI}: 1.3-2.5$, $p<0.001)$, but not ethnicity $(p=0.84)$, or socioeconomic status $(p=0.45)$ or gender $(p=0.81)$.

Low-performance was associated with: socioeconomic disadvantage $(\mathrm{OR}=2.0$, CI:1.3-3.0, $p=0.003) ; 10.7 \%$ (37/345) of socioeconomically disadvantaged participants reported low-performance compared to $6.6 \%(85 / 1286)$ of advantaged participants; Male gender (OR = 1.7, CI:1.1-2.5, $p=0.01) ; 9.1 \%(79 / 872)$ of males reported low-performance compared to $5.8 \%(43 / 741)$ of females; and Traveller ethnicity $(\mathrm{OR}=3.0, \mathrm{CI}: 1.3-7.0, p=0.008) ; 14.0 \%$ (21/151) of Traveller participants reported low-performance, the corresponding percentages for White and non-White were $7.0 \%(92 / 1282)$ and $5.0 \%(9 / 182)$ respectively. Low-performance was not associated with urban/rural living $(p=0.66)$.

Over two-thirds of low-performing participants (67\% of 6-7-year-olds and $69 \%$ of 12-13-year-olds) had no eye examination within 12 months of data collection. Unless otherwise stated the 6-7-year-olds and 12-13-year-olds are herewith analysed separately.

\section{Distance vision (3 m)}

Distance vision was significantly better amongst high-performing than average-performing and low-performing 6-7-year-olds $(p<0.001)$; similarly among 12-13-yearold $(p=0.02)$ participants (Table 1 and Figure 1 in which a higher value indicates poorer vision). 
Table 1. The relationship between school-performance in 722 6-7-years-old and 890 12-13years-old participants and presenting vision (distance $3 \mathrm{~m}$ and near $40 \mathrm{~cm}$ ), presenting stereovision and the presenting amplitude of accommodation.

\begin{tabular}{|c|c|c|c|c|}
\hline Presenting vision $\dagger$ & $\begin{array}{c}\text { High- } \\
\text { performance }\end{array}$ & $\begin{array}{c}\text { Average- } \\
\text { performance }\end{array}$ & $\begin{array}{c}\text { Low- } \\
\text { performance }\end{array}$ & $\begin{array}{c}P \text { - } \\
\text { value }\end{array}$ \\
\hline & $\begin{array}{l}6-7 \text { years } \\
\text { mean } \pm S D\end{array}$ & mean $\pm \mathrm{SD}$ & mean $\pm S D$ & \\
\hline $\begin{array}{l}\text { Distance vision } \\
\text { (logMAR) }\end{array}$ & $-0.01 \pm 0.15$ & $0.00 \pm 0.15$ & $0.15 \pm 0.25$ & $<0.001$ \\
\hline Near vision (logMAR) & $0.07 \pm 0.18$ & $0.08 \pm 0.22$ & $0.23 \pm 0.35$ & $<0.001$ \\
\hline $\begin{array}{l}\text { Stereovision } \\
\quad \text { (arcseconds) }\end{array}$ & $150.4 \pm 217.7$ & $135.9 \pm 202.6$ & $282.0 \pm 325.8$ & $<0.001$ \\
\hline \multirow{2}{*}{$\begin{array}{l}\text { Accommodation } \\
\text { (Dioptres) }\end{array}$} & $14.0 \pm 4.2$ & $13.7 \pm 3.8$ & $11.4 \pm 4.9$ & $<0.001$ \\
\hline & $\begin{array}{l}12-13 \text { years } \\
\text { mean } \pm \mathrm{SD}\end{array}$ & mean $\pm \mathrm{SD}$ & mean $\pm \mathrm{SD}$ & \\
\hline $\begin{array}{l}\text { Distance vision } \\
\text { (logMAR) }\end{array}$ & $-0.05 \pm 0.23$ & $-0.03 \pm 0.19$ & $0.00 \pm 0.24$ & 0.03 \\
\hline Near vision (logMAR) & $0.03 \pm 0.12$ & 0.04 & $0.07 \pm 0.18$ & 0.02 \\
\hline $\begin{array}{l}\text { Stereovision } \\
\quad \text { (arcseconds) }\end{array}$ & $87.6 \pm 163.9$ & $95.1 \pm 190.0$ & $149.4 \pm 252.3$ & 0.001 \\
\hline $\begin{array}{l}\text { Accommodation } \\
\text { (Dioptres) }\end{array}$ & $12.2 \pm 3.2$ & $12.1 \pm 3.8$ & $11.1 \pm 3.4$ & 0.24 \\
\hline
\end{tabular}

$\dagger$ Measurements taken with participants spectacles if worn; Boldface indicates statistically significant $P<$ 0.05 ; standard deviation (SD).

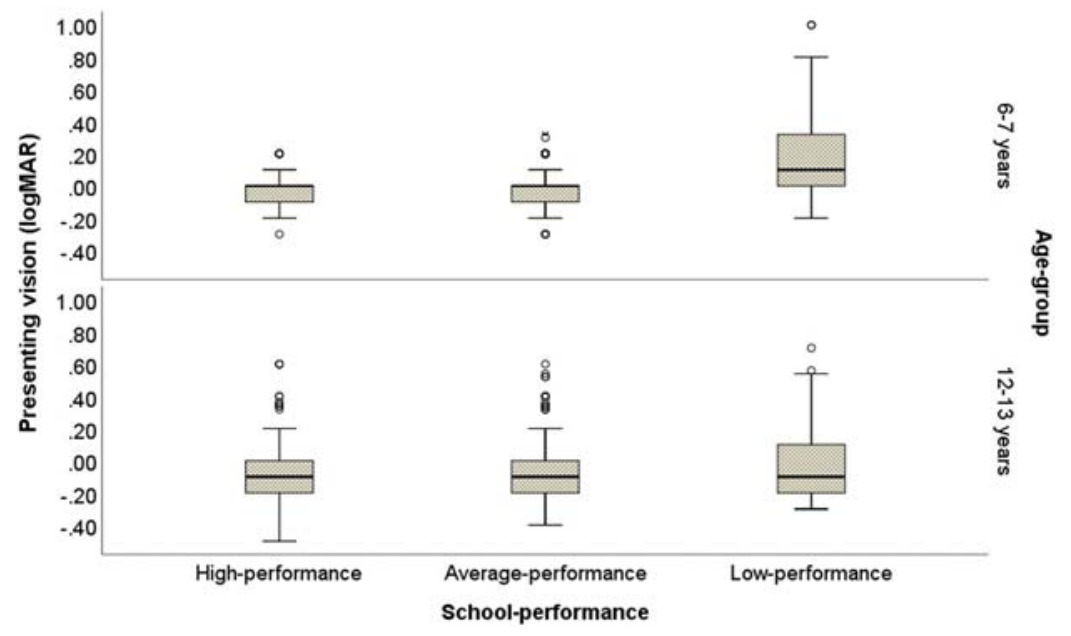

Figure 1. The distribution of distance vision (presenting with spectacles if worn) in 6-7-yearolds (top image) and 12-13 year-olds (bottom image) by parent-reported school performance category. On average, distance vision in low-performing 6-7-year-olds was significantly poorer than average-performing and high-performing 6-7-year-olds. 


\section{Near vision $(40 \mathrm{~cm})$}

Near vision was significantly better amongst high-performing, than average-performing, and low-performing 6-7-year-olds $(p<0.001)$; similarily in $12-13$-year-olds $(p<$ 0.001) (Table 1).

\section{Stereovision}

Stereovision was significantly better amongst high-performing than average-performing and low-performing 6-7-year-olds $(p<0.001)$; correspondingly in 12-13-year-olds $(p=0.001)$ (Table 1 and Figure 2 in which a higher value indicates poorer stereovision).

\section{Amplitude of accommodation}

Poorer accommodation was associated with low-performance in the 6-7-year-olds ( $p$ $<0.001)$, but not the 12-13-year-olds $(p=0.24)$ (Table 1$)$.

\section{Presenting visual impairment}

Six-seven-year-olds: PVI was associated with low-performance $(\mathrm{OR}=11.2, \mathrm{CI}: 4.8-27$, $p<0.001)$ (Figure 3). Of the 67 low-performing 6-7-years-olds, $11(16.4 \%)$ had PVI; seven $(10.5 \%)$ of which reported no history of spectacle wear; two $(3.0 \%)$ required updated spectacles, and two (3\%) did not have their spectacles at school.

Twelve-thirteen-year-olds: PVI was associated with low-performance $(\mathrm{OR}=3.3$, CI:1.5-9.1, $p=0.02$ ) (Figure 3); of the 55 low-performing 12-13-year-olds five (9\%) had PVI, of which two reported no history of spectacle wear, two were at school without their spectacles, and one required updated spectacles.

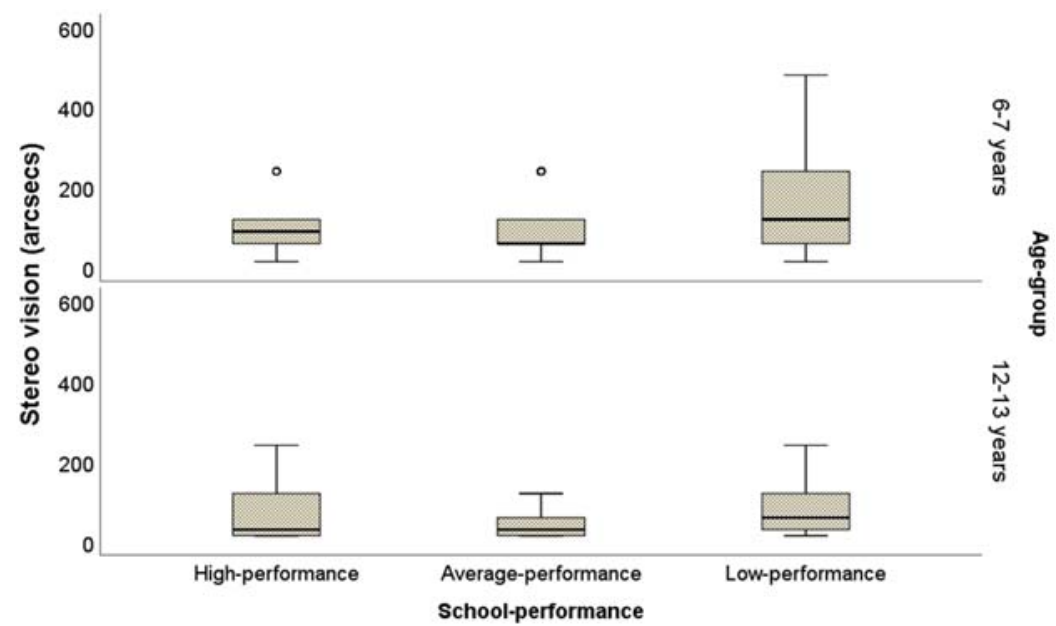

Figure 2. The distribution of stereoacuity (arcseconds) in 6-7-year-olds (top image) and 1213 year-olds (bottom image) by parent-reported school performance category. Low-performing participants had significantly poorer stereoacuity than average-performing and high-performing participants in both age-groups. 


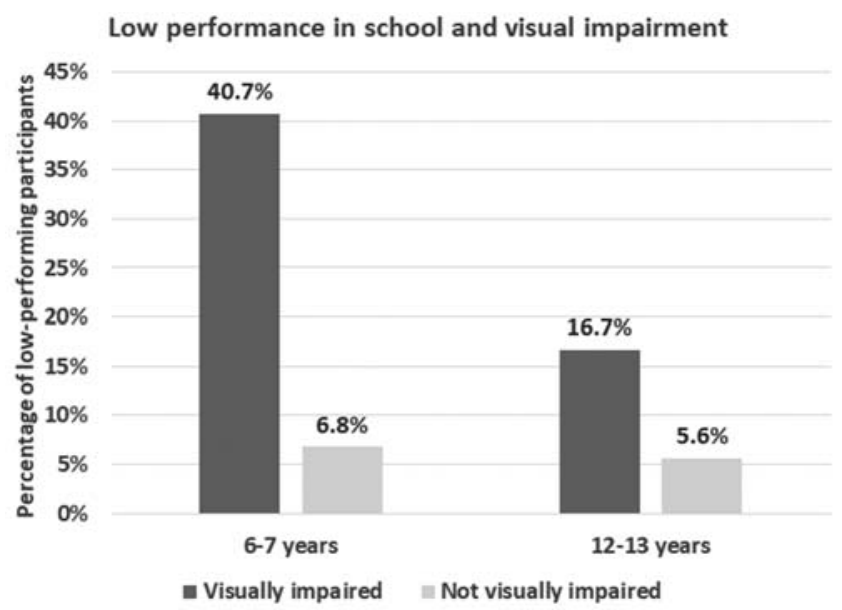

Figure 3. The relationship between presenting visual impairment and low-performance in school. Amongst participants with presenting visual impairment, $40.7 \%$ of $6-7$-year-olds and $16.7 \%$ of $12-13$-year-olds reported low-performance. The corresponding percentages for participants without visual impairment were $6.8 \%$ and $5.6 \%$ respectively.

\section{Spectacle wear compliance}

Amongst low-performing participants, four (6.3\%) 6-7-year-olds and eight (14.8\%) 12-13-year-olds did not have their spectacles in school.

\section{Eye examinations}

All low-performing 6-7-year-olds with PVI (11 participants) reported not having had their eyes tested during the 12 months before data collection. The corresponding numbers in the older cohort were three of five participants.

\section{Uncorrected clinically significant refractive error}

Emmetropia (absence of clinically significant refractive error) (OR $=1.4$, CI:1.1$1.8, p<0.001)$ was associated with high performance in both age-groups. Myopia (OR $=1.8, \mathrm{CI}: 1.2-2.7, p=0.003)$ was associated with high-performance in 12-13-year-olds but not in 6-7-year-olds $(p=0.27)$. Uncorrected hyperopia was associated with low-performance ( $\mathrm{OR}=2.7, \mathrm{CI}: 1.1-7.0, p=0.04)$; amongst uncorrected 6-7-year-old hyperopic participants, 23.8\% (5/21) reported low-performance compared to $9.5 \%$ (2/21) low-performance in corrected hyperopic 6-7year-olds.

Uncorrected astigmatism was associated with low-performance $(\mathrm{OR}=2.1$, CI:1.1-3.1, $p<0.001)$ in both age cohorts. Amongst uncorrected astigmatic 6-7year-olds, $37 \%$ (10/27) reported low-performance compared to $10.7 \%(3 / 28)$ of corrected astigmatic participants. Amongst 12-13-year-olds, 11\% (4/38) with uncorrected astigmatism reported low-performance in school, there were no low-performing 1213-year-old participants with corrected astigmatism. 


\section{Amblyopia}

Amblyopia was associated with low-performance in 6-7-year-olds (OR = 7.7, CI:4.014.3, $p<0.0001)$ and 12-13-year-olds $(\mathrm{OR}=5.6, \mathrm{CI}: 1.7-17.5, p=0.002)$ (Figure 4). Fitting a logistic regression model relating parent-reported school performance to the amblyopia and stereoacuity categories jointly (abnormal stereoacuity $\geq 240$ arcseconds otherwise normal) revealed both amblyopia $(\mathrm{OR}=3.5, \mathrm{CI}: 1.7-6.7, p=$ $0.001)$ and stereoacuity $(\mathrm{OR}=2.3, \mathrm{CI}: 1.4-4.0, p=0.002)$ remained significantly related to low-performance.

The effect of amblyopia treatment on parent-reported school performance was also investigated. Controlling for age, participants with amblyopia (never treated) were 3.7 times (CI:1.5-8.3, $p=0.004)$ more likely to report low-performance than those without amblyopia (never treated), and 3.6 times (CI:1.1-12.5, $p=0.04$ ) more likely to report low-performance than participants successfully treated for amblyopia (Figure 5).

\section{Strabismus}

Strabismus (misaligned eyes) was associated with low-performance $(\mathrm{OR}=2.1$, CI:1.1-4.0, $p=0.03$ ). All low-performing strabismic participants were esotropic. Fitting a logistic regression model relating parent-reported school performance to the amblyopia and strabismus jointly revealed strabismus was no longer associated with low-performance $(p=0.44)$, whereas amblyopia remained strongly associated with low-performance $(\mathrm{OR}=5.0, \mathrm{CI}: 2.9-8.8, p<0.0001)$.

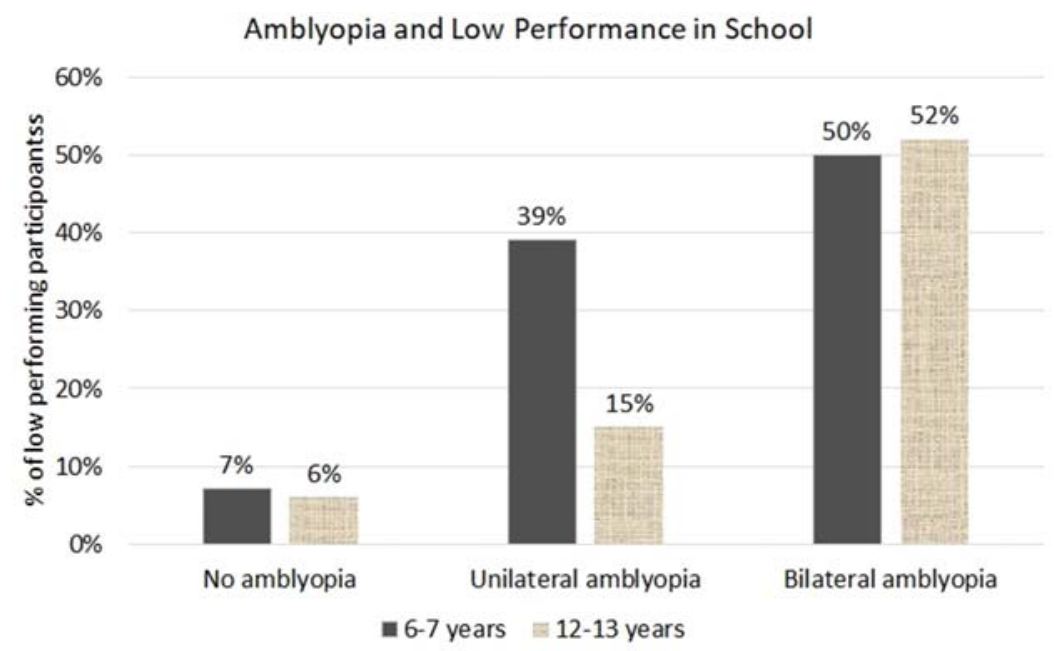

Figure 4. The relationship between amblyopia prevalence and low-performance in school. Of the 6-7-year-olds: $50 \%(4 / 8)$ of participants with bilateral amblyopia, 39.5\% (15/38) with unilateral amblyopia and 6.9\% (47/682) of non-amblyopic 6-7-year-olds reported low-performance. Of the 12-13-year-olds: 52\% (4/7) with bilateral amblyopia, $15.2 \%$ (5/33) with unilateral amblyopia and 5.7\% (49/858) without amblyopia reported low-performance. 


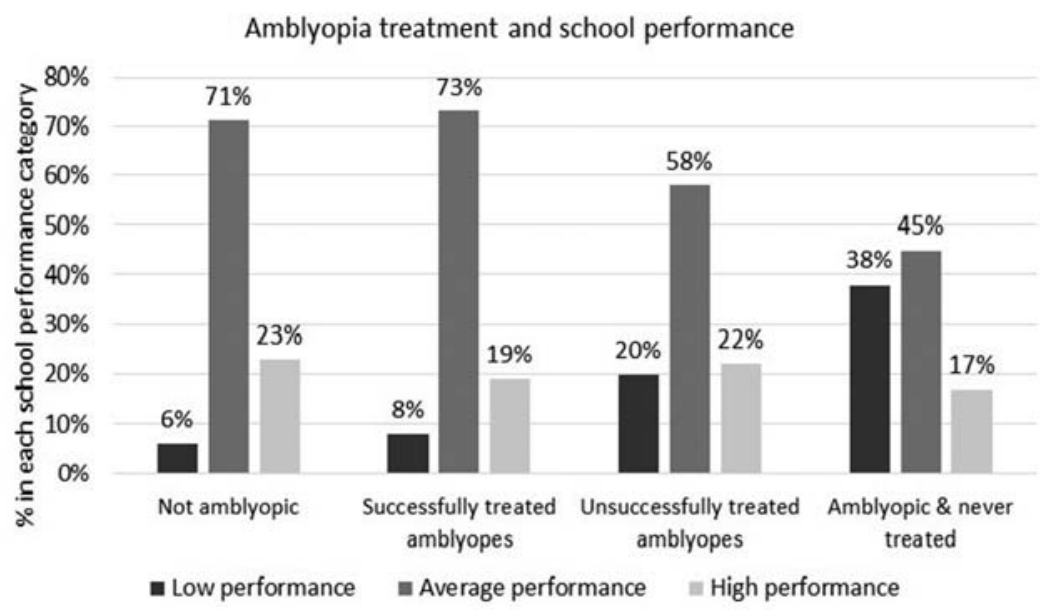

Figure 5. Percentage of participants who reported low-performance, average-performance, and high-performance in each of the following categories: not amblyopic with no history of treatment (1,453 participants), successfully treated amblyopes (79 participants), unsuccessfully treated amblyopes (31 participants), and amblyopic and no history of amblyopia treatment (40 participants).

\section{Colour vision}

Controlling for gender, defective colour-vision was associated with low-performance $(\mathrm{OR}=4.7, \mathrm{CI}: 1.5-14.3, p=0.01)$.

\section{Discussion}

This study is the first to explore the relationship between parent-reported school performance and vision in children attending mainstream schools in Ireland. Study findings demonstrate an association between uncorrected refractive error (long-sightedness and astigmatism), untreated amblyopia (lazy eye), PVI (inability to see half of a standard eye test chart with either eye in the distance and near), diminished stereoacuity (three-dimensional vision), and defective colour vision with low-performance in school. Following focus-group feedback, school academic performance data was based on how parents/guardians perceived their child's performance in school when compared to their peers. Therefore, children in socioeconomically disadvantaged schools were compared to children in the same environment and children attending other schools were compared to their peers. Hence, the present study addressed the association between how parents/guardians perceived their child's performance in school (qualitative analysis) and various aspects of vision (quantitative analysis). Quantitative analysis provides the empirical evidence necessary for clinical practitioners. Whereas, qualitative analysis supports the personal and experiential 'knowing' which is critical to the interpretation of study findings and their application to clinical practice (Malterud 2001). Furthermore, qualitative assessment methods are crucial to understanding community needs and issues, providing researchers with a better understanding of 
the meaning and implications of quantitative study findings (Malterud 2001). As patient-recorded outcome measures are now routinely used in health settings and essential when updating health policy (Tadić et al. 2013), feedback from parents/ guardians regarding their child's school academic performance provides useful information that may be more context-specific than test scores of mathematical ability or reading speed.

In line with previous studies, including with the PISA worldwide study (OECD 2016), the present study found low-performance associated with male gender (Weaver-Hightower 2003), socioeconomic disadvantage (Bruce et al. 2016), and ethnicity (Hoff 2013).

\section{Presenting vision}

Concurring with previous studies (Goldstand, Koslowe, and Parush 2005; Maples 2003), reduced distance VA was associated with low-performance in both agegroups. Distance VA demand in classrooms varies depending on the position in the classroom, level of illumination and whether the material is presented on a board/ smart-board (Narayanasamy et al. 2016; Negiloni, Ramani, and Sudhir 2017; 2019). However, the mean distance VA in low-performing 6-7-year-olds was poorer than the VA threshold level $(0.3 \log$ MAR) reported in the literature (Narayanasamy et al. 2016; Negiloni, Ramani, and Sudhir 2017). Additionally, PVI was associated with low-performance in both age-cohorts; children with PVI do not have the adequate vision threshold $(0.3 \log M A R)$ in either eye required to read material from a board/smart-board (Langford and Hug 2010; Narayanasamy et al. 2016). Thus, highlighting the importance of routine assessment of visual task demands and the visual skill levels required by children in school classrooms to inform educators of their student's visual requirements (Negiloni, Ramani, and Sudhir 2017).

Reduced near VA was associated with low-performance in both age-groups, which is unsurprising given the importance of near vision in the learning environment (Narayanasamy et al. 2016); over half of the school day involves sustained vision at 20$25 \mathrm{~cm}$. Moreover, the VA demand for children aged 10-12 years to sustain fluent reading was previously reported at $0.33 \pm 0.09 \log$ MAR (Narayanasamy et al. 2016); hence, many low-performing participants (mean vision at near $0.23 \pm$ $0.35 \log$ MAR) may not have adequate acuity to maintain sustained near work. Furthermore, in-school vision screening in Ireland is limited to a measurement of distance vision (Health Service Executive 2005); hence, children with reduced near vision may miss an opportunity for early intervention if their distance vision meets the screening cut-off $(0.2 \log$ MAR $)$.

\section{Refractive error}

The association established in the present study between uncorrected hyperopia (long-sightedness) and academic underperformance aligns with the Vision in Preschoolers Study and the Child Health and Education Study (Stewart-Brown, Haslum, and Butler 2008; VIP-HIP Study Group 2016). Traditionally, hyperopia $\leq+3.00 \mathrm{D}$ is rarely corrected in children aged 6-7-years as they are considered to have adequate accommodation to compensate for near visual tasks (Arnold 2004). However, the present study demonstrated low-performing children had significantly 
lower mean amplitude of accommodation, especially in the 6-7-year-old cohort. Prior research involving 10-12-year-olds reported the average reading distance at $23 \mathrm{~cm}$ (range $20 \mathrm{~cm}$ to $25 \mathrm{~cm}$ ) hence 4-5D of accommodation are required to see at near, and, as accommodative amplitude should be twice the dioptric demand, 8-10D of accommodation is necessary during near work in the classroom (Narayanasamy et al. 2016). Thus, low-performing participants may not have adequate accommodation (mean $(\mathrm{SD}): 11.4 \pm 4.9 \mathrm{D})$ required to sustain near fixation. Indeed, objectively measured accommodation may be lower than the subjectively measured push-up test used in the present study (Anderson et al. 2008). Furthermore, accommodation is rarely routinely checked in childhood as children are presumed to have adequate accommodation to see at near (Woodhouse et al. 1993), given accommodation decreases with age in the typical population and symptoms associated with difficulty reading are usually first experienced in middle age (45-years-old). Based on the results of the current study near VA and objectively measured accommodation (such as dynamic retinoscopy) ought to be routinely checked in schoolchildren.

Uncorrected astigmatism was associated with low-performance in the present study in agreement with the literature. For example, Harvey et al. (2016) reported reading fluency significantly reduced in students with uncorrected bilateral astigmatism, but not when corrected, compared to their non-astigmatic peers. Likewise, Narayanasamy et al. (2015) demonstrated simulated bilateral astigmatic blur resulted in reduced comprehension, reading speed and accuracy in 10-year-old Australians highlighting the challenges uncorrected astigmats experience in school, which has important implications for schoolchildren in Ireland, where significant amounts of uncorrected astigmatism exist (Harrington et al. 2019a).

Of further concern was the substantial number of children at school without their prescribed spectacles, many of whom were socioeconomically disadvantaged (Harrington et al. 2019a). Prescribing spectacles to children who need them can improve academic performance (Ma et al. 2014; Slavin et al. 2018; Yi et al. 2015), which is essential for children with special educational needs (Black et al. 2019), resulting in increased classroom engagement and reduced 'off-task' behaviour (Black et al. 2019). Moreover, cognitive ability in low-income preschoolers with uncorrected refractive error significantly improved following just six-weeks of spectacle wear (Roch-Levecq et al. 2008).

Furthermore, the prevalence of myopia is increasing globally; one in five 12-13year-olds in Ireland are myopic (Harrington et al. 2019a). Children with myopia will not have the threshold level of VA needed to see detail on the white or blackboard in school. Hence, compliance with spectacle wear in school requires coordinated public health policy responses at both the child and parental level (Harrington et al. 2019b).

\section{Amblyopia, strabismus and binocular vision}

Overall, proportionally more parents/guardians of 6-7-year-olds with strabismus (misaligned eyes) reported their children were low-performing than parents/guardians of orthotropic (straight-eyed) participants, in agreement with previous studies (Reed, Kraft, and Buncic 2004; Woodhouse, Griffiths, and Gedling 2000). Furthermore, similar to Reed, Kraft, and Buncic (2004), strabismus was associated with low-performance in the younger cohort and not the older group in the present 
study. Hence, its possible children may adapt or develop coping strategies for their strabismus. Interestingly, controlling for amblyopia, the association between strabismus and school-performance was no longer significant, suggesting the presence of strabismus (a cosmetically visible eye defect) alone is not a marker for academic difficulties; instead it is the relationship between strabismus and amblyopia which was strongly associated with low-performance. Indeed, Narayanasamy et al. (2014) demonstrated simulated monocular hyperopic blur was significantly associated with impaired academic performance, particularly when the 11-year-old participants were involved in sustained near visual tasks.

The association found between amblyopia and low-performance aligns with Khalaj et al. (2011) and Kugathasan et al. (2019). Moreover, the reduced levels of low-performance amongst participants successfully treated for amblyopia reinforce the importance of early detection and compliance with amblyopia treatment. This finding is crucial in Ireland where persistent amblyopia (post-traditional treatment age) prevalence is high ( $4.5 \%$ in children aged $12-13$ years) and associated with socioeconomic disadvantage and poor compliance with spectacle wear (Harrington et al. 2019b).

Previous studies demonstrated a relationship between amblyopia and reading speed (Kelly et al. 2015), transcribing (Kelly et al. 2018), and disrupted reading ability and accuracy (Kugathasan et al. 2019). Kugathasan et al. (2019) proposed children with amblyopia, may benefit from using texts with reduced crowding and from time allowances for tasks involving reading. In contrast, Rahi, Cumberland, and Peckham (2006) attributed quality of life issues associated with amblyopia to amblyopia treatment (wearing an eyepatch) and not the visual disruption. For example, Carlton and Kaltenthaler (2011) reported low self-esteem, negative self-image, bullying and teasing are associated with amblyopia treatment. However, successful amblyopia treatment to improve VA was associated with significantly reduced levels of low-performance in the present study. Hence, addressing amblyopia and completing amblyopia treatment early in childhood when treatment is more likely to be successful (Holmes 2011), and during a period before children become increasingly more self-aware and susceptible to ridicule and feelings of inferiority (Erikson's psychosocial stage 4 (5-12-years-old): industry versus inferiority) (Erikson 1968) is essential. Thus, it is necessary to integrate vision, educational and psychosocial implications of amblyopia treatment (Koklanis, Abel, and Aroni 2006).

The association between reduced/abnormal stereoacuity and low-performance concurs with Taylor-Kulp (1999). Controlling for amblyopia, the relationship between abnormal stereoacuity and low-performance remained. Stereoacuity is a measure of binocular vision (three-dimensional vision), which is affected by reduced VA, inaccurate accommodation and ocular alignment ( $\mathrm{Li}$ et al. 2016). Furthermore, Ponsonby et al. (2013) demonstrated orthoptic interventions (a programme of eye exercises) to improve stereoacuity improved literacy in children to a greater extent than providing parental literacy support alone.

\section{Colour vision deficiency}

Controlling for gender, participants with defective colour vision performed less well than classmates in the current study, aligning with findings in Italian schoolchildren (Gallo et al. 1998). In contrast, Cumberland, Rahi, and Peckham (2004) reported 
children with defective colour vision did as well as their peers educationally, and the authors queried the rationale for colour-vision screening in schools. Indeed, as per the Best Health Revisited HSE guidelines, colour vision is not routinely checked in schoolchildren in Ireland (HSE 2005). However, colour is used extensively as a didactic tool in education, and more recent research demonstrated defective colour vision associated with slow learning (Gallo et al. 2003). Additionally, Steward and Cole (1989) and Gallo et al. (2003) established many individuals are unaware of their defective colour vision. Hence, early screening is vital to inform teaching staff and assist children in developing adaptive strategies to support learning and inform career choice, which is limited by defective colour vision (Cole 2004).

\section{Public awareness}

The majority of participants (68\%) reported by their parents/guardians as low-performing in school had not had an eye examination within the 12 months before data collection. Furthermore, focus-group feedback revealed parents/guardians of low-performing children might be uncomfortable about sharing specific academic data. However, many low-performing children had PVI, a level of vision too poor to obtain a driving licence, demonstrating a possible lack of public awareness as to the importance of clear and accurate vision in children's development (Sharma et al. 2012). Whether parents were unaware of the association between school-performance and a child's ability to see clearly or unaware of how to access an eye examination for their child was not investigated in the present study. Furthermore, parents may have other commitments such as work or dependants in the home, which mean they are unable to bring their child for an eye examination (Sharma et al. 2012). As both PVI and low-performance were associated with socioeconomic disadvantage in the present study, some families may have been unable to afford private eyecare for their child. In Ireland, children without a medical card are not entitled to free eye tests with a high street optometrist. The waiting lists for publically funded eye tests is currently over two years in Ireland (Power et al. 2017), the consequence is many children are not accessing an eye examination either before commencing school or when a child is performing below average in school.

Early vision testing requires parental knowledge of the importance of vision testing for children. Early childhood interventions enhance children's wellbeing, as demonstrated by the Chicago longitudinal (18 years) study where, every $\$ 1.00$ invested in health, social services and preschool education to low-income children in public schools returned \$7.50 to society (Reynolds, Temple, and Ou 2003). Membreno et al. (2002) estimated economic benefit of amblyopia treatment was $\$ 22$ return to the Gross Domestic Product for every $\$ 1$ invested; this return is especially enhanced due to the early intervention of amblyopia treatment and the subsequent lifelong impact on income. Thus, the impact of poor vision, on children's educational performance is a public health issue (Black et al. 2019), which has financial implications for the community due to lost earnings (Membreno et al. 2002), and a range of associated health issues such as anxiety and depression (Hayes et al. 2019; Leo et al. 1999). Notably, Traveller and socioeconomically disadvantaged participants were disproportionately affected in this study with higher levels of both PVI and low-performance. While this paper does not seek to investigate the impact of specific policies on academic performance, the results do suggest that both parent-reported school performance and 
PVI are complex issues that require a coordinated approach including recognition of interrelated determinants of health. O'Donnell et al. (2016) demonstrated culturallyspecific policy responses, including innovative ways of accessing primary care for marginalised groups, are vital to address existing inequalities. Likewise, novel ways of engaging constructively with marginalised groups are needed to address existing eye-health and educational inequalities in Ireland.

The high number of low-performing children with PVI and no history of primary eyecare identified in the present study, highlight the gaps and the possible lack of optimal integration with current childhood health services in Ireland. Additionally, the acknowledged delays in eyecare follow up of over two years in Ireland (Murphy 2017) from when issues are reported, may be a contributor to the level of unaddressed vision issues identified in the study. Thus, study findings highlight the importance of earlier testing of children's vision, ideally in advance of starting school, which will allow the development of adaptive policies to assist those children in school in achieving their academic potential generating consequential societal benefits by increasing the number of better-performing students in school.

The strengths of this study include the large sample size, random school selection and the high questionnaire completion rate (>99\%). Parent-reported outcomes of school performance instead of objectively measured academic scores is a study limitation. Standardised outcome measures to assess the relationship between academic achievement and vision are essential (Hopkins et al. 2019); however, public engagement during the design stage of the present study revealed the difficulties and sensitivities associated with that aim. Hence, gaps remain concerning specific aspects of vision and their relationship with particular aspects of academic achievement. Further research is therefore required to examine what level of visual impairment is likely to interfere with various aspects of learning. To address these limitations, increasing public awareness of the importance of vision in children's education is imperative, as is involving public representatives and relevant stakeholders at the design stage of any future study to prevent participation bias and provide data to inform clinical decision-making. Furthermore, due to the cross-sectional nature of the data, it is not possible to conclude that unaddressed visual issues are responsible for low-performance in school. Hence, further studies, including longitudinal studies, are recommended to assess the extent and magnitude of the relationship between vision and how well children perform academically in school.

\section{Conclusion}

This study revealed low-performance in children in mainstream schools in Ireland was associated with undetected or untreated visual impairment due to uncorrected refractive error and amblyopia, with marginalised communities disproportionally affected. Poor stereoacuity and defective colour vision were additional factors with schoolchildren aged 6-7 years, particularly affected by unaddressed visual issues. Children presenting with academic performance challenges ought to have a comprehensive eye examination, to detect potential vision problems for early intervention, thus minimising any negative impact they will have on educational outcomes. Study findings suggest that addressing vision and academic performance inequalities requires coordinated policy responses at both the child and community level. Specific and culturally-appropriate public education programmes highlighting the importance 
of comprehensive eye examinations for all children, including the consequences of untreated and undetected visual problems, ideally in advance of starting school is a study recommendation. Reporting of visual outcomes will create better awareness of vision issues such as defective colour vision in school-age children to determine educational requirements specific to children with these visual issues, thereby enabling teachers and parents/guardians to develop adaptive teaching strategies to help susceptible children achieve their academic potential while progressing through school.

\section{Patient and public involvement}

The study was supported by a patient advisory group, which provided input to the programme of research. Parents/legal guardians of participants collaborated with us for the design of the study, the informational material to support the data collection and participant and school involvement, and assess the burden of participation from the patient's perspective. At the end of the study, results and findings were provided to all participants.

Data availability statement: No additional unpublished data from the study are available.

\section{Notes}

1. G*Power software is used to calculate statistical power to determine the appropriate sample size to detect a "true" effect when it exists

2. A unit of measurement of the optical power of a lens- reciprocal of the lens focal length in metres

3. The difference in dioptres between the steepest and shallowest curvature of the lens/cornea.

\section{Acknowledgement}

The authors would like to express their appreciation to Dr Jim Stack (Waterford Institute of Technology, Ireland), Professor John Kearney (Epidemiology, School of Biological Sciences, Technological University Dublin, Ireland), and Professor Kathryn Saunders (School of Biomedical Sciences, Ulster University, Northern Ireland) for their valuable input in the Ireland Eye Study. The authors would also like to acknowledge the support and participation of the schools, the children and their parents and guardians in the Ireland Eye Study.

\section{Disclosure statement}

The authors report no conflicts of interest.

\section{Funding}

This work was supported by Technological University Dublin Fiosraigh Scholarship: [Grant Number N/A]; Association of Optometrists Ireland: [Grant Number N/A]; Irish Opticians Board: [Grant Number N/A].

\section{Notes on contributors}

Dr Siofra Harrington, PhD, lecturer in Optometry and clinical tutor in Technological University Dublin, principal investigator Ireland Eye Study, research interests include ametropia, 
amblyopia and visual impairment in children, public health and vision screening, myopia management, binocular vision, colour vision, sports vision and school vision.

Dr Peter Davison, PhD, formerly Senior Lecturer in Optometry at Technological University Dublin. National Optometry Centre Colour Vision Assessment Unit head. His research interests include evaluating colour vision tests, macular pigment density effects on visual functions, cataract patients postoperative vision prediction, night-vision, and road traffic accidents visual correlations.

Dr Veronica O'Dwyer, PhD, lecturer and clinical tutor in Optometry in Technological University Dublin, research interests include schoolchildren ametropia, amblyopia and vision impairment; diet/macular pigment in age-related macular degeneration; Demodex folliculorum and dry eye and contact lens wear impact on refractive surgery outcomes.

\section{ORCID}

Siofra Harrington (D) http://orcid.org/0000-0003-2667-1796

\section{References}

Anderson, H., G. Hentz, A. Glasser, K. Stuebing, and R. Manny. 2008. "Minus-LensStimulated Accommodative Amplitude Decreases Sigmoidally with Age: A Study of Objectively Measured Accommodative Amplitudes from Age 3." Investigative Opthalmology \& Visual Science 49 (7): 2919. doi:10.1167/iovs.07-1492.

Arnold, R. 2004. "Pseudo-False Positive Eye/Vision Photoscreening Due to Accommodative Insufficiency. A Serendipitous Benefit for Poor Readers?" Binocular Vision \& Strabismus Quarterly 19 (2): 75-80. http://www.ncbi.nlm.nih.gov/pubmed/15180592.

Atkinson, J., S. Anker, M. Nardini, O. Braddick, C. Hughes, S. Rae, J. Wattam-Bell, and S. Atkinson. 2002. "Infant Vision Screening Predicts Failures on Motor and Cognitive Tests up to School Age.” Strabismus 10 (3): 187-198. doi:10.1076/stra.10.3.187.8125.

Birch, E., Y. Castañeda, C. Cheng-Patel, S. Morale, K. Kelly, C. Beauchamp, and A. Webber. 2018. "Self-Perception of School-Aged Children With Amblyopia and Its Association With Reading Speed and Motor Skills." JAMA Ophthalmology November. doi:10.1001/ jamaophthalmol.2018.5527.

Black, S., E. McConnell, L. McKerr, J. McClelland, J. Little, K. Dillenburger, A. Jackson, P. Anketell, and K. Saunders. 2019. "In-School Eyecare in Special Education Settings Has Measurable Benefits for Children's Vision and Behaviour." Edited by Celestino Rodríguez." PLOS ONE 14 (8): e0220480. doi:10.1371/journal.pone.0220480.

Bruce, A., L. Fairley, B. Chambers, J. Wright, and T. Sheldon. 2016. "Impact of Visual Acuity on Developing Literacy at Age 4-5 Years: A Cohort-Nested Cross-Sectional Study." BMJ Open 6 (2): e010434. doi:10.1136/bmjopen-2015-010434.

Carlton, J., and E. Kaltenthaler. 2011. "Amblyopia and Quality of Life: A Systematic Review." Eye 25 (4): 403-413. doi:10.1038/eye.2011.4.

Chen, A., W. Bleything, and Y. Lim. 2011. "Relating Vision Status to Academic Achievement among Year-2 School Children in Malaysia." Optometry 82 (5): 267-273. doi:10.1016/j. optm.2011.02.004.

Christian, L., K. Nandakumar, P. Hrynchak, and E. Irving. 2018. "Visual and Binocular Status in Elementary School Children with a Reading Problem." Journal of Optometry 11 (3): 160166. doi:10.1016/j.optom.2017.09.003.

Cole, B. 2004. "The Handicap of Abnormal Colour Vision." Clinical and Experimental Optometry 87 (4-5): 258-275. doi:10.1111/j.1444-0938.2004.tb05056.

Collins, D. 2003. "Pretesting Survey Instruments: An Overview of Cognitive Methods." Quality of Life Research 12 (3): 229-238. doi:10.1023/A:1023254226592.

Cumberland, P., J. Rahi, and C. Peckham. 2004. "Impact of Congenital Colour Vision Deficiency on Education and Unintentional Injuries: Findings from the 1958 British Birth 
Cohort.” BMJ (Clinical Research Ed.) 329 (7474): 1074-1075. doi:10.1136/bmj.38176. 685208.F7.

Diamond, K. 1987. "Predicting School Problems from Preschool Developmental Screening: A Four-Year Follow-Up of the Revised Denver Developmental Screening Test and the Role of Parent Report." Journal of the Division for Early Childhood 11 (3): 247-253. doi:10.1177/ 105381518701100307

Diamond, K., and J. Squires. 1993. "The Role of Parental Report in the Screening and Assessment of Young Children." Journal of Early Intervention 17 (2): 107-115. doi:10. 1177/105381519301700203.

Dirani, M., S. Shekar, and P. Baird. 2008. "The Role of Educational Attainment in Refraction: The Genes in Myopia (GEM) Twin Study." Investigative Ophthalmology \& Visual Science 49 (2): 534-538.

Ehri, L. 2005. "Learning to Read Words: Theory, Findings, and Issues." Scientific Studies of Reading 9 (2): 167-188. doi:10.1207/s1532799xssr0902_4.

Erikson, E. 1968. Psychosocial Identity - In International Encyclopedia of the Social Sciences. New York: Crowell-Collier.

Gallo, P., M. Panza, P. Lantieri, D. Risso, G. Conforti, P. Lagonia, A. Piro, G. Tagarelli, and A. Tagarelli. 2003. "Some Psychological Aspects of Colour Blindness at School: A Field Study in Calabria and Basilicata (Southern Italy)." Color Research and Application 28 (3): 216-220. doi:10.1002/col.10148.

Gallo, P., M. Panza, F. Viviani, and P. Lantieri. 1998. "Congenital Dyschromatopsia and School Achievement." Perceptual and Motor Skills 86 (2): 563-569. doi:10.2466/pms.1998. 86.2.563.

Gilbert, E., S. Carmi, S. Ennis, J. Wilson, and G. Cavalleri. 2017. "Genomic Insights Into the Population Structure and History of the Irish Travellers." Scientific Reports 7: 1-12. doi:10. 1038/srep42187.

Glascoe, F. 1997. "Parents' Concerns About Children's Development: Prescreening Technique or Screening Test?" Pediatrics 99 (4): 522-528. doi:10.1542/peds.99.4.522.

Goldstand, S., K. Koslowe, and S. Parush. 2005. "Vision, Visual-Information Processing, and Academic Performance among Seventh-Grade Schoolchildren: A More Significant Relationship Than We Thought?" American Journal of Occupational Therapy 59 (4): 377_ 389. doi:10.5014/ajot.59.4.377.

Harrington, Síofra, Jim Stack, Kathryn Saunders, and Veronica O’Dwyer. 2019a. "Refractive error and visual impairment in Ireland schoolchildren." British Journal of Ophthalmology 103 (8): 1112-1118. https://doi.org/10.1136/bjophthalmol-2018-312573.

Harrington, Síofra, Karen Breslin, Veronica O'Dwyer, and Kathryn Saunders. 2019b. "Comparison of Amblyopia in Schoolchildren in Ireland and Northern Ireland: A Population-Based Observational Cross-Sectional Analysis of a Treatable Childhood Visual Deficit.” BMJ Open 9 (8): e031066. https://doi.org/10.1136/bmjopen-2019-031066.

Harvey, E., J. Miller, J. Twelker, and A. Davis. 2016. "Reading Fluency in School-Aged Children with Bilateral Astigmatism." Optometry and Vision Science 93 (2): 118-125. doi:10.1097/OPX.0000000000000779.

Hayes, J., S. Picot, D. Osborn, G. Lewis, C. Dalman, and A. Lundin. 2019. "Visual Acuity in Late Adolescence and Future Psychosis Risk in a Cohort of 1 Million Men." Schizophrenia Bulletin 45 (3): 571-578. doi:10.1093/schbul/sby084.

Health Service Executive. 2005. "Best Health for Children Revisted Best Health for Children Revisited: Report from the National Core Child Health Programme Review Group to the Health Service Executive. Dublin: HSE.” Dub. Available at: https://www.hse.ie/eng/ services/publications/children/appendix-2-best-health-for-children-revisted.pdf.

Helveston, E., J. Weber, K. Miller, K. Robertson, G. Hohberger, R. Estes, F. Ellis, N. Pick, and B. Helveston. 1985. "Visual Function and Academic Performance." American Journal of Ophthalmology 99 (3): 346-355. doi:10.1016/0002-9394(85)90368-X.

Hoff, E. 2013. "Interpreting the Early Language Trajectories of Children from Low-SES and Language Minority Homes: Implications for Closing Achievement Gaps.” Developmental Psychology 49 (1): 4-14. doi:10.1037/a0027238.

Holmes, J. 2011. "Effect of Age on Response to Amblyopia Treatment in Children." Archives of Ophthalmology 129 (11): 1451. doi:10.1001/archophthalmol.2011.179. 
Hopkins, Shelley, Alex Black, Sonia White, and Joanne Wood. 2019. "Visual Information Processing Skills Are Associated with Academic Performance in Grade 2 School Children." Acta Ophthalmologica June. doi:10.1111/aos.14172.

Hopkins, S., S. Narayanasamy, S. Vincent, G. Sampson, and J. Wood. 2019. "Do Reduced Visual Acuity and Refractive Error Affect Classroom Performance?" Clinical and Experimental Optometry August: cxo.12953. doi:10.1111/cxo.12953.

Ip, Jenny, D. Robaei, A. Kifley, J. Wang, K. Rose, and P. Mitchell. 2008. "Prevalence of Hyperopia and Associations with Eye Findings in 6- and 12-Year-Olds." Ophthalmology 115 (4): 678-685.e1. doi:10.1016/J.OPHTHA.2007.04.061.

Kelly, K., R. Jost, A. De La Cruz, and E. Birch. 2015. "Amblyopic Children Read More Slowly Than Controls Under Natural, Binocular Reading Conditions." Journal of American Association for Pediatric Ophthalmology and Strabismus 19 (6): 515-520. doi:10.1016/j. jaapos.2015.09.002.

Kelly, K., R. Jost, A. De La Cruz, and E. Birch. 2018. "Multiple-Choice Answer Form Completion Time in Children With Amblyopia and Strabismus." JAMA Ophthalmology 136 (8): 938. doi:10.1001/jamaophthalmol.2018.2295.

Khalaj, M., I. Mohammadi Zeidi, M. Gasemi, and A. Keshtkar. 2011. "The Effect of Amblyopia on Educational Activities of Students Aged 9 -15." J. Biomedical Science and Engineering 4: 516-521. doi:10.4236/jbise.2011.47066.

Koklanis, K., L. Abel, and R. Aroni. 2006. "Psychosocial Impact of Amblyopia and Its Treatment: A Multidisciplinary Study." Clinical and Experimental Ophthalmology 34 (8): 743-750. doi:10.1111/j.1442-9071.2006.01317.x.

Kugathasan, L., M. Partanen, V. Chu, C. Lyons, and D. Giaschi. 2019. "Reading Ability of Children Treated for Amblyopia." Vision Research 156 (March): 28-38. doi:10.1016/j. visres.2019.01.001.

Kulp, M., and P. Schmidt. 1996. "Visual Predictors of Reading Performance in Kindergarten and First Grade Children." Optometry and Vision Science: Official Publication of the American Academy of Optometry 73 (4): 255-262. http://www.ncbi.nlm.nih.gov/pubmed/ 8728493.

Langford, A., and T. Hug. 2010. "Visual Demands in Elementary School." Journal of Pediatric Ophthalmology and Strabismus 47 (3): 152-156. doi:10.3928/01913913-20090818-06.

Legge, G., and C. Bigelow. 2011. "Does Print Size Matter for Reading? A Review of Findings from Vision Science and Typography." Journal of Vision 11 (5): 1-22. doi:10.1167/11.5.1.

Leo, D., P. Hickey, G. Meneghel, and C. Cantor. 1999. "Blindness, Fear of Sight Loss, and Suicide." Psychosomatics 40 (4): 339-344. doi:10.1016/S0033-3182(99)71229-6.

Li, A. 2004. "Classroom Strategies for Improving and Enhancing Visual Skills in Students with Disabilities." SAGE Journals. Teaching Exceptional Children 36 (6): 38-46. doi:10.1177\% 2F004005990403600605.

Li, R., K. So, T. Wu, A. Craven, T. Tran, K. Gustafson, and D. Levi. 2016. "Monocular Blur Alters the Tuning Characteristics of Stereopsis for Spatial Frequency and Size." Royal Society Open Science 3 (9): 160273. doi:10.1098/rsos.160273.

Li, T., X. Zhou, J. Zhu, X. Tang, and X. Gu. 2019. "Effect of Cycloplegia on the Measurement of Refractive Error in Chinese Children." Clinical and Experimental Optometry 102: 160165. doi:10.1111/cxo.12829.

Logan, Nicola, Parth Shah, Alicja Rudnicka, Bernard Gilmartin, and Christopher Owen. 2011. "Childhood Ethnic Differences in Ametropia and Ocular Biometry: The Aston Eye Study." Ophthalmic and Physiological Optics 31 (5): 550-558. https://doi.org/10.1111/j. 1475-1313.2011.00862.X.

Ma, X., Z. Zhou, H. Yi, X. Pang, Y. Shi, Q. Chen, M. Meltzer, et al. 2014. "Effect of Providing Free Glasses on Children's Educational Outcomes in China: Cluster Randomized Controlled Trial." BMJ, doi:10.1136/bmj.g5740.

Malterud, K. 2001. "Qualitative Research: Standards, Challenges, and Guidelines." The Lancet 358 (9280): 483-488. doi:10.1016/S0140-6736(01)05627-6.

Maples, W. 2003. "Visual Factors That Significantly Impact Academic Performance." Optometry (St. Louis, Mo.) 74 (1): 35-49. http://www.ncbi.nlm.nih.gov/pubmed/12539891. 
Membreno, J., M. Brown, G. Brown, S. Sharma, and G. Beauchamp. 2002. "A Cost-Utility Analysis of Therapy for Amblyopia." Ophthalmology 109 (12): 2265-2271. http://www. ncbi.nlm.nih.gov/pubmed/12466169.

Murphy, B. (Health Service Executive). 2017. "Primary Care Eye Services Review Group Report." 1-108. file:///C:/Users/302491/Downloads/Eye Review Report - Final.pdf.

Narayanasamy, S., S. Vincent, G. Sampson, and J. Wood. 2014. "Simulated Hyperopic Anisometropia and Reading, Visual Information Processing, and Reading-Related Eye Movement Performance in Children." Investigative Ophthalmology and Visual Science 55 (12): 8015-8023. doi:10.1167/iovs.14-15347.

Narayanasamy, S., S. Vincent, G. Sampson, and J. Wood. 2015. "Simulated Astigmatism Impairs Academic-Related Performance in Children." Ophthalmic and Physiological Optics 35 (1): 8-18. doi:10.1111/opo.12165.

Narayanasamy, S., S. Vincent, G. Sampson, and J. Wood. 2016. "Visual Demands in Modern Australian Primary School Classrooms." Clinical and Experimental Optometry 99 (3): 233 240. doi:10.1111/cxo.12365.

Negiloni, K., K. Ramani, and R. Sudhir. 2017. "Do School Classrooms Meet the Visual Requirements of Children and Recommended Vision Standards?" Edited by Gianni Virgili." PLOS ONE 12 (4): e0174983. doi:10.1371/journal.pone.0174983.

Negiloni, K., K. Ramani, and R. Sudhir. 2019. "Environmental Factors in School Classrooms: How They Influence Visual Task Demand on Children." Edited by Madhavi Bhargava." PLOS ONE 14 (1): e210299. doi:10.1371/journal.pone.0210299.

Negrel, Dominique, Eugenio Maul, Gopal P. Pokharel, Jialiang Zhao, and Leon B. Ellwein. 2000. "Refractive Error Study in Children: Sampling and Measurement Methods for a Multi-Country Survey." American Journal of Ophthalmology 129 (4): 421-426. doi:10. 1016/S0002-9394(99)00455-9.

O’Donnell, P., E. Tierney, A. O'Carroll, D. Nurse, and A. Mac Farlane. 2016. "Exploring Levers and Barriers to Accessing Primary Care for Marginalised Groups and Identifying Their Priorities for Primary Care Provision: a Participatory Learning and Action Research Study.” Int J Equity Health 15: 197. doi:10.1186/s12939-016-0487-5.

O'Donoghue, L., J. F. McClelland, N. S. Logan, R. Rudnicka, C. G. Owen, and K. J. Saunders. 2010. "Refractive Error and Visual Impairment in School Children in Northern Ireland." The British Journal of Ophthalmology 94 (9): 1155-1159. doi:10.1136/bjo.2009.176040.

O’Donoghue, L., A. Rudnicka, J. McClelland, N. Logan, and K. Saunders. 2012. "Visual Acuity Measures Do Not Reliably Detect Childhood Refractive Error - an Epidemiological Study.” PLoS ONE 7 (3), doi:10.1371/journal.pone.0034441.

OECD. 2016. "Low-Performing Students Why They Fall Behind and How To Help Them Succeed, Programme for International Student Assessment." Paris. https://doi.org/10. 1787/9789264250246-en.

Ojaimi, Elvis, Kathryn a Rose, Wayne Smith, Ian G Morgan, Frank J Martin, and Paul Mitchell. 2005. "Methods for a Population-Based Study of Myopia and Other Eye Conditions in School Children: The Sydney Myopia Study." Ophthalmic Epidemiology 12 (1): 59-69. doi:10.1080/09286580490921296.

Onal, S., E. Toker, Z. Akingol, G. Arslan, S. Ertan, C. Turan, and O. Kaplan. 2007. "Refractive Errors of Medical Students in Turkey: One Year Follow-up of Refraction and Biometry." Optometry and Vision Science 84 (3): 175-180. doi:10.1097/OPX.0b013e3180335c52.

Ponsonby, A.-L., K. Smith, E. Williamson, D. Bridge, A. Carmichael, T. Dwyer, A. Jacobs, and J. Keeffe. 2013. "Poor Stereoacuity Among Children With Poor Literacy." Optometry and Vision Science 90 (1): 75-83. doi:10.1097/OPX.0b013e3182780dd0.

Ponsonby, A.-L., E. Williamson, K. Smith, D. Bridge, A. Carmichael, A. Jacobs, J. Burrill, N. Ollington, J. Keeffe, and T. Dwyer. 2013. "Children with Low Literacy and Poor Stereoacuity: An Evaluation of Complex Interventions in a Community-Based Randomized Trial." Ophthalmic Epidemiology 16 (5): 311-321. http://www.ncbi.nlm.nih. gov/pubmed/19874111.

Power, W., P. Barry, P. Moriarty, and S. Kelly. 2017. "Clinical Strategy And Programmes Directorate Patient Safety First Tús Áite Do Shábháilteacht Othar National Clinical Programme for Ophthalmology Model of Eye Care." https://www.hse.ie/eng/services/ publications/clinical-strategy-and-programmes/model-of-eye-care.pdf. 
Rahi, J., P. Cumberland, and C. Peckham. 2006. "Does Amblyopia Affect Educational, Health, and Social Outcomes? Findings from the 1958 British Birth Cohort." BMJ 332 (7545): 820825. doi:10.1136/bmj.38751.597963.AE.

Rahi, J., and C. Gilbert. 2012. "Epidemiology and the Worldwide Impact of Visual Impairment in Children." Pediatric Ophthalmology and Strabismus, Expert Consult-Online and Print, 4: Pediatric Ophthalmology and Strabismus 1.

Reed, M., S. Kraft, and R. Buncic. 2004. "Parents' Observations of the Academic and Nonacademic Performance of Children with Strabismus." Journal of Visual Impairment \& Blindness 98 (5): 276-288. doi:10.1177/0145482X0409800503.

Reynolds, A., J. Temple, and S.-R. Ou. 2003. "School-Based Early Intervention and Child Well-Being in the Chicago Longitudinal Study." Child Welfare League of America 82 (5): 633-656.

Roch-Levecq, A.-C. 2008. "Ametropia, Preschoolers' Cognitive Abilities, and Effects of Spectacle Correction." Archives of Ophthalmology 126 (2): 252. doi:10.1001/ archophthalmol.2007.36.

Roch-Levecq, A.-C., B. Brody, R. Thomas, and S. Brown. 2008. "Ametropia, Preschoolers' Cognitive Abilities, and Effects of Spectacle Correction." Archives of Ophthalmology 126 (2): 252-258. doi:10.1001/archophthalmol.2007.36.

Scheiman, Mitchell M., and Michael W. Rouse. 2006. Optometric Management of LearningRelated Vision Problems. 2nd. St Louis:: Elsevier Health Sciences.

Sharma, A., N. Congdon, M. Patel, and C. Gilbert. 2012. "School-Based Approaches to the Correction of Refractive Error in Children." Survey of Ophthalmology 57 (3): 272-283. doi:10.1016/j.survophthal.2011.11.002.

Skarzyński, H., and A. Piotrowska. 2012. "Prevention of Communication Disorders Screening Pre-School and School-Age Children for Problems with Hearing, Vision and Speech: European Consensus Statement.” Medical Science Monitor 18 (4). doi:10.12659/ MSM.882603.

Slavin, R., M. Collins, M. Repka, D. Friedman, L. Mudie, J. Owoeye, and N. Madden. 2018. "In Plain Sight: Reading Outcomes of Providing Eyeglasses to Disadvantaged Children." Journal of Education for Students Placed at Risk 23 (3): 250-258. doi:10.1080/10824669. 2018.1477602.

Smith, T., K. Frick, B. Holden, T. Fricke, and K. Naidoo. 2009. "Potential Lost Productivity Resulting from the Global Burden of Uncorrected Refractive Error." Bulletin of the World Health Organization 87 (6): 431-437. doi:10.2471/BLT.08.055673.

Steward, J., and B. Cole. 1989. "What Do Color Vision Defectives Say About Everyday Tasks?" Optometry and Vision Science: Official Publication of the American Academy of Optometry 66 (5): 288-295. http://www.ncbi.nlm.nih.gov/pubmed/2787492.

Stewart-Brown, S., M. Haslum, and N. Butler. 2008. "Educational Attainment of 10-Year-Old Children with Treated and Untreated Visual Defects." Developmental Medicine \& Child Neurology 27 (4): 504-513. doi:10.1111/j.1469-8749.1985.tb04575.x.

Sylva, K. 1997. "Critical Periods in Childhood Learning.” British Medical Bulletin 53 (1): 185197. https://academic.oup.com/bmb/article-abstract/53/1/185/285447.

Tadić, V., A. Hogan, N. Sobti, R. Knowles, and J. Rahi. 2013. "Patient-Reported Outcome Measures (PROMs) in Paediatric Ophthalmology: A Systematic Review.” British Journal of Ophthalmology 97 (11): 1369-1381. doi:10.1136/bjophthalmol-2013-303350.

Taylor-Kulp, M. 1999. "Relationship Between Visual Motor Integration Skill and Academic Performance in Kindergarten Through Third Grade." Optometry and Vision Science: Official Publication of the American Academy of Optometry 76 (3): 159-163. http://www. ncbi.nlm.nih.gov/pubmed/10213445.

VIP-HIP Study Group, The Vision In Preschoolers - Hyperopia In Preschoolers (VIP - HIP). 2016. "Uncorrected Hyperopia and Preschool Early Literacy: Results of the Vision in Preschoolers-Hyperopia in Preschoolers (VIP-HIP) Study.” Ophthalmology 123 (4): 681689. doi:10.1016/j.ophtha.2015.11.023.

Weaver-Hightower, M. 2003. "The 'Boy Turn' in Research on Gender and Education." Review of Educational Research 73 (4): 471-498. doi:10.3102/00346543073004471.

Webber, Ann L. 2018. "The Functional Impact of Amblyopia." Clinical and Experimental Optometry 101 (4): 443-450. doi:10.1111/cxo.12663. 
Wilkins, A., R. Cleave, N. Grayson, and L. Wilson. 2009. "Typography for Children May Be Inappropriately Designed." Journal of Research in Reading 32 (4): 402-412. doi:10.1111/j. 1467-9817.2009.01402.x.

Williams, C., G. Miller, and S. Saw. 2008. "A Comparison of Measures of Reading and Intelligence as Risk Factors for the Development of Myopia in a UK Cohort of Children.” The British Journal of Ophthalmology 92 (8): 1117-1121. doi:10.1136/bjo.2007. 128256.

Wood, J., A. Black, S. Hopkins, and S. White. 2018. "Vision and Academic Performance in Primary School Children." Ophthalmic and Physiological Optics 38 (5): 516-524. doi:10. 1111/opo.12582.

Woodhouse, J., C. Griffiths, and A. Gedling. 2000. "The Prevalence of Ocular Defects and the Provision of Eye Care in Adults with Learning Disabilities Living in the Community." Ophthalmic \& Physiological Optics 20 (2): 79-89. http://www.ncbi.nlm.nih.gov/pubmed/ 10829129.

Woodhouse, J., J. Meades, S. Leat, and K. Saunders. 1993. "Reduced Accommodation in Children with Down Syndrome." Investigative Ophthalmology and Visual Science 34 (7): 2382-2387.

Xiao, Ou, Ian Morgan, Leon Ellwein, and Mingguang He. 2015. "Prevalence of Amblyopia in School-Aged Children and Variations by Age, Gender, and Ethnicity in a Multi-Country Refractive Error Study.” Ophthalmology, 1-8. doi:10.1016/j.ophtha.2015.05.034.

Yi, Hongmei, Haiqing Zhang, Xiaochen Ma, Linxiu Zhang, Xiuqin Wang, Ling Jin, Kovin Naidoo, et al. 2015. "Impact of Free Glasses and a Teacher Incentive on Children's Use of Eyeglasses: A Cluster-Randomized Controlled Trial." American Journal of Ophthalmology 160 (5). doi:10.1016/j.ajo.2015.08.006. 